\title{
O Estágio de Nível Médio nas Escolas de Ensino Fundamental da Prefeitura de Maracanaú
}

\section{Danúbia Nogueira da Rocha Chaves}

Mestre em Planejamento em Políticas Publicas - UECE

\section{Jeannette Filomeno Pouchain Ramos}

Doutora em Educação pela Universidade Federal do Ceará - UEC

Professora do Instituto de Humanidade e Letras (IHL) da UNILAB

\section{Resumo}

O texto procura elucidar como constrói-se o estágio de estudantes de nivel médio numa instituição pública municipal, no contexto neoliberal, com o consequente desmonte do Estado, e as práticas da desregulamentação, flexibilização e precarização do trabalho, por meio das subcontratações, terceirizações e exclusão de direitos sociais, determinando um processo de formação excludente, acrítico e para atender aos interesses do capital. Abordaremos na perspectiva da Gestão de Recursos Humanos como se desenvolve esse estágio, buscando compreender se essa modalidade de estágio evolui, como complemento ao ensino ou como precarização do trabalho. A análise dos dados obtidos na pesquisa de campo realizada com vinte e dois estagiários de nível médio, dois supervisores de estágio e dois gestores públicos, permitiu concluir que, o estágio de nível médio se constitui em precarização do trabalho juvenil, caracterizado pela realização de várias atividades sem relação direta com o plano de atividades de estágio e, principalmente pela inexistência dos direitos trabalhistas e previdenciários que barateia a contratação dessa mão de obra, tornando-a atrativa ao capital e excludente do trabalho digno.

Palavras-chave: Formação. Trabalho. Juventudes. Estágio. Políticas Públicas 


\begin{abstract}
The text seeks to elucidate how the stage of middle-level students is built in a municipal public institution, in the neoliberal context, with the consequent dismantling of the State, and the practices of deregulation, flexibilization and labor precarization, through subcontracting, outsourcing and Exclusion of social rights, determining a process of formation excluding, uncritical and to meet the interests of capital. We will approach from the perspective of Human Resources Management how this stage develops, trying to understand if this type of internship evolves, as a complement to teaching or as precarious work. The analysis of the data obtained in the field research carried out with twenty-two mid-level trainees, two trainee supervisors and two public managers allowed us to conclude that the middle-level stage constitutes a precariousness of youth work, characterized by the accomplishment of several Activities that are not directly related to the internship plan, and mainly due to the lack of labor and social security rights, which reduces the hiring of this workforce, making it attractive to capital and excluding decent work.
\end{abstract}

Key words: Training. Job. Youths. Internship. Public Policies. 


\section{Introdução}

Com o advento do neoliberalismo e o consequente desmonte do Estado, mediante intenso processo de privatização e as práticas de desregulamentação, flexibilização e precarização do trabalho, representadas pelas subcontratações, terceirizações e exclusão de direitos trabalhistas e previdenciários, criando paralelamente um processo de formação excludente, acrítico e para atender aos ditames do capital, constrói-se o cenário de contextualização da prática de estágio de estudantes em instituições públicas e privadas de forma dissociada do ensino. Com base nesse cenário, estudou-se a prática do estágio de nível médio, através da pesquisa concluída para o mestrado, realizada nas escolas de ensino fundamental da Prefeitura de Maracanaú, na perspectiva da Gestão de Recursos Humanos, vislumbrando-se investigar o que seria produzido a partir desse instituto, bem como os tipos de relações construídas nesse processo, o valor agregado estabelecido para o estagiário e para a Administração Pública municipal, enquanto instituição governamental, e finalmente o resultado dessa prática, com destaque para as necessidades que atenderia e de quem, perscrutando-se se essa modalidade de estágio evolui, na prática, como complemento ao ensino ou como mera precarização do trabalho.

Para contextualizar a Instituição pública municipal, temos uma cultura organizacional alicerçada no contexto neoliberal, imbuída de um discurso voltado para o viés da redução de custos para otimização do trabalho, na histórica escassez de pessoal no serviço público e pela onda da inserção do jovem no mercado de trabalho, além do constante apelo social de minimização da pobreza e exclusão social o que nos motivou a direcionar o estudo na perspectiva de desvendar esse contexto no qual uma significativa parcela da juventude local está inserida que é o Programa de Estágios da Prefeitura de Maracanaú - subprocesso da área de desenvolvimento de pessoas da Secretaria de Recursos Humanos e Patrimoniais da Prefeitura de Maracanaú, criado pela Lei Municipal oㅜ 562, de 9 de setembro de 1997 (MARACANAÚ, 1997), objetivando, de acordo com o texto legal, complementar o ensino e a aprendizagem.

Segundo levantamento realizado em setembro de 2015 por meio do sistema de gestão de pessoas, o Estágio de nível médio reunia à época 343 jovens estudantes, representando $52 \%$ da população de estagiários ativos na instituição.

De acordo com os estudos realizados, entende-se que a prática de estágio de nível médio envolve muitos fatores e que sua consecução requer que se compreenda o papel do supervisor no campo enquanto agente diretamente corresponsável por esta prática, possibilitando aos estagiários a construção de uma aprendizagem efetiva dos conhecimentos científicos e o desenvolvimento de habilidades indispensáveis para uma atuação social que os tornem capazes de propô-la e serem dela protagonistas, bem como entender o modo como a instituição concebe essa modalidade de estágio e finalmente compreender o estágio em 
si, imerso a vários tipos de subcontratações existentes na lógica do capital para justificar a exploração do trabalhador por intermédio da precarização da sua força produtiva.

Para comprovar essa hipótese, realizou-se pesquisa qualitativa acerca do Programa de estágios sob o olhar de vinte e dois estagiários, através de grupo focal, que receberam o codinome de corpos celestes do sistema solar: Plutão, Ceres, Éris, Makemake, Haumea, Caronte, Mercúrio, Vênus, Terra, Marte, Júpiter, Saturno, Urano, Netuno , Disnomia, Namaka, Hiiaka, Asteroide, Vesta, Eros, Halley e McNaugh. E entrevista semiestruturada com dois supervisores de estágio e dois gestores públicos. Neste artigo será abordado como se desenvolve o estágio de nível médio nas escolas de ensino fundamental da Prefeitura, buscando entender como historicamente o instituto de estágio surge e se fortalece na perspectiva da precarização do trabalho, dissociado do ensino e do preparo para o trabalho, abordaremos o programa institucional de estágios, bem como as mudanças estruturais na relação entre escola e trabalho das juventudes, a prática do estágio em si e as considerações finais.

\section{O programa de estágio na cidade industrial de Mara- canaú}

Maracanaú localiza-se no estado do Ceará, Nordeste do Brasil. É o terceiro colocado em termos de contingente populacional entre os municípios que formam a grande Fortaleza, abaixo somente de Fortaleza e Caucaia. O município foi criado pela Lei Estadual ㄲo 10.811, de 4 de julho de 1983 (CEARÁ, 1983). Segundo dados do IBGE (2010), possui uma população de 209.057 habitantes. É considerado o mais importante Distrito Industrial do Estado, concentrando $1 / 3$ da produção cearense no setor, e o segundo colocado no ranking de arrecadação do Imposto sobre Operações Relativas à Circulação de Mercadorias e sobre Prestações de Serviços de Transporte Interestadual, Intermunicipal e de Comunicação (ICMS). Reúne aproximadamente 3.760 unidades empresas ativas em diversas áreas, ocupando 61.544 pessoas, segundo o último Censo (IBGE, 2010).

De acordo com os dados do último Censo Demográfico do IBGE (2010) a população jovem de Maracanaú está representada nas seguintes faixas etárias: tem-se 21.177 jovens entre 15 e 19 anos, 22.317 na faixa dos 20 aos 24 anos e 20.677 na faixa dos 25 aos 29 anos de idade, totalizando 64.171 jovens no Município. Ainda de acordo com o IBGE, tem-se em Maracanaú um total de 1.104 jovens na faixa etária de 15 a 29 anos de idade que nunca frequentaram creche ou escola, estando totalmente excluídos do sistema de ensino local, e 11.156 jovens que frequentam o ensino médio regular, população na qual se encontram os 
estagiários de nível médio da Prefeitura de Maracanaú, que será melhor caracterizada mais adiante.

Inicia-se esse estudo a partir da evolução do conceito de estágio, que, vem sofrendo modificações desde a Idade Média, quando concebido como simples atividade de acompanhamento prático a um mestre da época até a contemporaneidade, em que é considerado atividade curricular prática.

Segundo Colombo et al. (2014) o termo estágio, em latim medieval stagium, foi citado pela primeira vez na literatura no ano de 1080 para designar local ou residência para morar, em alusão à sua derivação do latim clássico stare, que significava estar em um determinado lugar. No ano de 1630, na França, a literatura cunha o termo stage para denominar o período transitório de treinamento de um sacerdote destinado a torná-lo apto ao desempenho de seu ofício, que ocorria em uma Igreja, na qual o sacerdote passaria a residir antes de tomar posse do cargo. Nesse contexto, infere-se que essa terminologia, desde a sua concepção, esteve atrelada à aprendizagem desenvolvida em local previamente estabelecido sob supervisão.

No Brasil, essas mudanças conceituais foram marcadas pela evolução da legislação educacional e a proliferação de conflitos de interesses, que se dividiam entre a defesa do estágio atrelado à escola e a do estágio vinculado às empresas, como esclarecem os autores:

Os debates em torno de uma nova legislação sobre estágio ocorrida no Congresso Nacional Brasileiro, a partir da primeira década do século XXI, demonstraram a existência de um confronto entre aqueles que defendiam o estágio com foco no interesse da escola e os que focavam o interesse das empresas. (COLOMBO et al., 2014, p. 172).

Na continuidade, a legislação educacional vai avançando no sentido de garantir o viés educativo da prática de estágio e se inicia um processo de discussão em torno da função desse período de treinamento, que segundo os autores vem

[...] reforçar o aprendizado profissional do educando através da experiência prática. Esta se torna ainda mais proveitosa quando está ligada à realidade econômica em que a escola está inserida, pois, com a interação - entre o aluno, a empresa e a escola -, há um ganho pedagógico para todos, visto que grande parte da bagagem teórica da sala de aula vai de encontro à situação concreta e do cotidiano, no mundo econômico real (COLOMBO et al., 2014, p. 173). 
Nessa discussão, a função do estágio estaria diretamente relacionada ao conteúdo escolar, porém essa teoria é refutada no que diz respeito ao estágio de nível médio, pois, a formação escolar nesse nível de ensino é propedêutica e não há vínculo entre o conteúdo curricular e a prática do estágio. Ainda de acordo com os autores, "a prática do estágio não pode ser confundida com a aplicação de mão de obra barata (precarizada) a ser utilizada nas empresas" (COLOMBO et al., 2014, p. 173), e é exatamente o que acontece na realidade investigada, como se verá no decorrer deste estudo. ${ }^{1}$ Em 2008 foi promulgada a Lei no11.788, - A chamada Nova Lei Geral do Estágio, (BRASIL, 2008) para dispor sobre os estágios e alterar a redação da Consolidação da Leis do Trabalho-CLT. A referida Lei apresenta o conceito de estágio em seu artigo 1ํ, que se transcreve na sequência (BRASIL, 2008):

[...] ato educativo escolar supervisionado, desenvolvido no ambiente de trabalho, que visa à preparação para o trabalho produtivo de educandos que estejam freqüentando o ensino regular em instituições de educação superior, de educação profissional, de ensino médio, da educação especial e dos anos finais do ensino fundamental, na modalidade profissional da educação de jovens e adultos.

1 A primeira legislação que fez menção a situação semelhante com a do estágio foi o Decreto no 20.294, de 12 de agosto de 1931 (BRASIL, 1931b), permitindo que a Sociedade Nacional de Agricultura (SNA) admitisse alunos mediante acordo firmado com o Ministério da Agricultura, recebendo uma porcentagem financeira anual por cada aluno matriculado.Somente no final da década de 1960, sob o regime militar, em 1967, é que o estágio escolar foi instituído nas faculdades e escolas técnicas mediante a Portaria ํำ1.002 (BRASIL, 1967), pelo então Ministro do Trabalho e da Previdência Social Sr. Jarbas Gonçalves Passarinho. A partir dessa norma, definiu-se a importância do estágio para complementar o ensino, bem como se determinou que sua ocorrência deveria ser orientada por um contrato cujas regras estabelecessem sua duração, carga horária, seguro contra acidentes e valor da bolsa, ao mesmo tempo em que explicitassem a impossibilidade de reconhecimento de vínculo empregatício, a inexistência de encargos sociais, o não pagamento de férias e do 13ํㅗ salário, mantendo-se dessa forma o compromisso do governo com a classe empresarial de continuar com a mesma política de estágio nascida em 1942. Em 11 de agosto de 1971 é publicada a Lei № 5.692(LDB) (BRASIL, 1971), que fixou as diretrizes e bases da Educação e previu o contrato de estágio como forma de cooperação entre empresas e escolas em seu artigo 6o e parágrafo único, visando proporcionar ao estudante uma relação mais próxima com a prática profissional. Segundo Colombo et al.: "[...] A LDB permitia a improvisação para o cumprimento legal desta complementação de formação, resultando em trabalho precário, pois o foco da oferta competia " á unidade interessada no estágio, em articulação com as instituições educacionais". O foco continuava a ser o do interesse do setor produtivo (empresas). [...] ( 2014, p. 175, grifos nossos)". 
Desse modo, tenta minimizar a exploração do trabalho do jovem estagiário, cabendo aos órgãos fiscalizadores a tarefa de verificar na prática, o cumprimento integral da legislação, evitando as práticas fraudulentas dos contratos de trabalho e da exploração da mão de obra dos estagiários.

Demonstramos abaixo o quadro de evolução cronólogica da implantação do programa de estágios na Prefeitura de Maracanaú, para entendermos a sua movimentação entre as diversas Secretarias, de acordo com a visão e interesse político sobre o mesmo.

\begin{tabular}{|c|c|c|c|}
\hline Lei Municipal & Nomenclatura & Objetivo & Coordenação \\
\hline $\begin{array}{l}\text { Lei № } 562 \text {, de } 9 \text { de } \\
\text { setembro de } 1997\end{array}$ & $\begin{array}{l}\text { Programa de Estágio } \\
\text { Curricular de Estu- } \\
\text { dante (Proece) }\end{array}$ & $\begin{array}{l}\text { Complementar o } \\
\text { ensino e a aprendi- } \\
\text { zagem }\end{array}$ & $\begin{array}{l}\text { Secretaria de Admi- } \\
\text { nistração }\end{array}$ \\
\hline $\begin{array}{l}\text { Lei № 912, de } 27 \text { de } \\
\text { agosto de } 2003\end{array}$ & $\begin{array}{l}\text { Projeto Jovem Esta- } \\
\text { giário }\end{array}$ & $\begin{array}{l}\text { Complementar o } \\
\text { ensino e a aprendi- } \\
\text { zagem e preparar } \\
\text { o jovem para sua } \\
\text { inserção no mercado } \\
\text { de trabalho }\end{array}$ & $\begin{array}{l}\text { Secretaria Extraordi- } \\
\text { nária do Trabalho e } \\
\text { da Juventude }\end{array}$ \\
\hline $\begin{array}{l}\text { Lei no } 1.349 \text {, de } 14 \text { de } \\
\text { novembro de } 2008\end{array}$ & Programa Estagiar & $\begin{array}{l}\text { Fomentar o aprendi- } \\
\text { zado,complementar } \\
\text { o ensino e preparar } \\
\text { o jovem para sua } \\
\text { inserção no mercado } \\
\text { de trabalho }\end{array}$ & $\begin{array}{l}\text { Secertaria de Recur- } \\
\text { sos Humanos e Patri- } \\
\text { moniais }\end{array}$ \\
\hline
\end{tabular}

Findos os esclarecimentos sobre a base legal do Programa Estagiar na Prefeitura de Maracanaú, ilustra-se, na continuidade, sua caraterização e o perfil dos estagiários, após levantamento realizado por intermédio do Sistema de Gestão de Pessoas da Secretaria de Recursos Humanos e Patrimoniais.

A Prefeitura de Maracanaú possui um total 9.285 servidores, de acordo com informações colhidas da folha de pagamento em setembro de 2015, entre os quais estão estagiários, servidores terceirizados, temporários, efetivos e ocupantes de cargos comissionados.

De acordo com os dados colhidos, tem-se a seguinte distribuição: dos 661 jovens estagiários, 343 são de nível médio, 84 são de nível técnico e 234 são de nível superior, e apresentam o seguinte perfil: 389 são do sexo feminino, representando 59\%, enquanto 272 são do sexo masculino, representando $41 \%$ do total de estagiários. 
Quanto à sua faixa etária, destaca-se que 604 jovens estão na faixa dos 16 aos 29 anos de idade, representando $91,4 \%$ do total, enquanto 49 jovens estão na faixa dos 30 aos 45 anos de idade, representando 7,4\%, e apenas 8 estão na faixa dos 46 aos 65 anos de idade, representando 1,2\% de adultos compondo o quadro de estagiários. Cada estagiário recebe uma bolsa que é mantida com recurso da Assistência Social, com variação de valores entre $R \$ 202,08$ e $R \$ 443,30$ (considerado o valor pago em setembro de 2015) por 4 horas diárias de serviços prestados na modalidade de estágio, de acordo com o nível de escolaridade e semestre, no caso dos estagiários de nível superior.

Ressalta-se que essa é a menor remuneração que o Município pratica em sua folha de pagamento, segundo dados da folha de pagamento do sistema de gestão em Recursos Humanos da Prefeitura.

No próximo tópico apresentam-se as mudanças estruturais na relação entre escola e trabalho das juventudes, bem como a prática de estágio de nível médio realizada na instituição pública municipal, palco das relações entre estagiários, gestores públicos e supervisores de estágio que reproduz o cenário de precarização do trabalho e os paradoxos entre formação, aprendizado e preparo para o trabalho.

\subsection{As mudanças estruturais na relação entre escola e trabalho das}

\section{juventudes}

Ao longo dos tempos, os conteúdos escolares tiverem que ser adaptados em atendimento às determinações reprodutivas em mutação no sistema do capital. Segundo Mészáros (2008), as determinações gerais do capital influenciam na Educação como todo, e não somente nas instituições formais responsáveis por fornecê-la, assegurando-se de que cada indivíduo assuma como suas as metas de reprodução do próprio sistema mediante processo de internalização da legitimidade da posição hierárquica social.

Desse modo, o processo educacional é balizado sob o prisma da legitimação da superioridade de uma classe sobre a outra, ou seja, manutenção dos interesses da classe hegemônica, reforçando seus princípios e ideologias. Ressalta-se que desde a sua origem a Educação surge para atender basicamente a duas necessidades, a de formação propedêutica para os nobres e a de preparação para o trabalho para os membros da classe subalterna. e atualmente se constitui em falta de universalização e dificuldade de acesso para a população da rede pública de ensino, dentre outros fatores.

Em pesquisa realizada para sua tese de doutorado, Ramos (2009) reúne alguns relatos apresentados por alunos do ensino médio de uma escola pública estadual, localizada no Município de Maracanaú-CE, contendo elementos relevantes para este estudo como veremos a seguir. 
Ramos (2009) evidenciou que 39\% dos estudantes entrevistados fizeram estágio durante o curso, e que esse fator, considerado como diferencial da escola sob o olhar dos

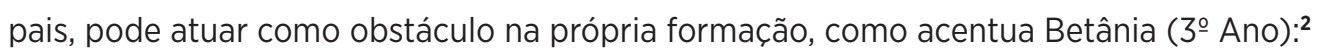

Um dado apresentado nessa pesquisa que vem colaborar sobremaneira com este estudo refere-se à iniciação do jovem no mundo do trabalho, que segundo a autora (RAMOS, 2009) ocorre a partir da prática dos estágios sem o devido acompanhamento, o que os transforma em atividade como qualquer outra desempenhada no mundo do trabalho, reforçando a hipótese de trabalho precário.

\begin{abstract}
A iniciação ao mundo do trabalho desenvolve-se por meio de estágios e, em média, 30\% dos estudantes acima de 16 anos participam, no entanto, estes não são acompanhados pela escola e terminam sendo uma atividade individual, cabendo aos estudantes fazer as reflexões necessárias para a análise crítica e criativa do processo de trabalho, do produto, das relações sociais no mundo do trabalho e consigo mesmo. (p. 172).
\end{abstract}

Nesse contexto, mesmo a pesquisa tendo sido realizada em apenas uma unidade educacional, demonstra claramente a distorção sobre o real objetivo do estágio e o modo como é visto pelo educador/ direção da unidade de ensino, cujo relato o descreve como medida disciplinadora. Pode-se verificar em suas próprias palavras que "se um estudante está com problema de comportamento, a escola pode inseri-lo no programa de estágio [...] [no qual] [...] muitas vezes ele melhora. Acontece isso com muitos alunos, a expressão do cara quando ele chega do estágio é diferente" (RAMOS, 2009, p. 173, grifos da autora).

Como forma de enriquecer essa discussão apresentam-se algumas contribuições de Pistrak (2005, p. 33), extraídas de sua obra Fundamentos da Escola do Trabalho, na qual aborda como objetivo da escola que the compete "[...] educar as crianças de acordo com as concepções, o espírito da realidade atual; esta deve invadir a escola, [...]; a escola deve viver no seio da realidade atual, adaptando-se a ela e organizando-a ativamente. (p. 33).

Compreende-se portanto que o papel da escola na formação da juventude consubstancia-se a partir da realidade atual, que requer a formação de cidadãos com capacidade crítica para interpretá-la e nela intervir enquanto sujeitos que a integram, e não meros objetos absorvedores de conteúdos direcionados para a dominação de uma classe por outra.

2 “à tarde o [sic] estudantes marcam para fazer trabalhos em grupos e não dava, porque estou no estágio. À noite eu chegava muito cansada e ainda ia pegar as atividades às pressas ou quando eu chegava ao colégio pegava de algum colega” (p.146-147). A estudante reconhece a importância do estágio na sua formação enquanto primeiro contato com o mundo do trabalho, porém relata que essa prática obstaculiza o rendimento escolar, interferindo negativamente no seu desenvolvimento. 
Para corroborar essa assertiva, apresentam-se as contribuições de Ivo Tonet (2003) em seu artigo "A Educação numa Encruzilhada", parte da obra Trabalho, Sociabilidade e Educação, na qual pontua que as crises atuais pelas quais passa o Brasil não poderiam deixar de atingir a Educação, o Trabalho, a Ciência, a Arte etc. e como tal processo de crise a educação é alvo das armadilhas do capital para se reinventar, transformando a Educação em uma simples mercadoria. $O$ autor reforça ainda que é possível acontecer outra Educação sim, na perspectiva de formação voltada para a emancipação humana:

[...] toda atividade educativa, teórica e prática, que pretenda contribuir para formar pessoas que caminhem no sentido de uma autêntica comunidade humana, deve nortear-se pela perspectiva da emancipação humana e não pela perspectiva da construção de um mundo cidadão (TONET, 2003, p. 212).

Na visão do autor, um mundo cidadão significa uma forma política de reprodução da sociabilidade, mantendo também a desigualdade social. Em face dessa situação, a escola precisa ser repensada quanto às suas funções e ao seu papel na formação das novas gerações, nas dimensões política, econômica, social, ética e cultural, de modo que seja comprometida com um sistema de ensino democrático, universal que busque a superação das injustiças e desigualdades sociais.

Segundo dados do Relatório do Fundo das Nações Unidas para a Infância (UNICEF, 2011) dos 4,3 milhões de brasileiros com idades entre 5 e 17 anos que exercem algum tipo de atividade laboral, 77\% (3,3 milhões) são jovens adolescentes de 14 a 17 anos de idade. Ressalta-se que a legislação brasileira proíbe o trabalho formal até os 16 anos de idade, exceto como aprendiz, a partir dos 14 anos. Nesse aspecto, o trabalho nessa categoria juvenil é considerado uma vulnerabilidade porque a atividade laboral nessa faixa etária, segundo o Relatório, quase sempre interfere na educação desses jovens, submetendo-os a riscos físicos e psicológicos, além dos riscos de acidentes e doenças profissionais.

Traçando esse panorama para a realidade local do município de Maracanaú, dados do IBGE (2010) revelam que 8.604 pessoas com 10 anos ou mais de idade frequentavam a escola e tinham ocupação, 75.852 pessoas nessa faixa etária não frequentavam a escola e estavam trabalhando e 56.760 pessoas não frequentavam a escola e nem estavam ocupadas, 34.983 somente estudavam e não tinham ocupação, enquanto 132.612 pessoas não frequentavam a escola.

Desses dados, infere-se que a grande maioria da população jovem, representando 132.612 pessoas, está excluída do sistema de ensino local, e que a segunda maior população, representando 75.852 pessoas, não está na escola e está trabalhando, reforçando as infor- 
mações divulgadas pelo Relatório Unicef (2011) de que o trabalho vulnerabiliza a população jovem, que não consegue dar continuidade aos estudos porque tem que trabalhar tornando-os vulneráveis, desse modo, o citado relatório (2011,p.35) descreve o panorama do trabalho do adolescente no Brasil como sendo:

Perigoso, insalubre, pouco ou nada remunerado, frágil em suas relações, [...] representa[ndo] uma vulnerabilidade que vem cedendo apenas aos poucos, ao longo dos anos, e parece sempre se alimentar de uma cultura da precariedade, gerando mais um ciclo de exclusão e violação de direitos, de desproteção e insegurança. (p. 35).

Na continuidade, aprofundam-se os conhecimentos na categoria Trabalho e Educação que, para Sousa et al. (2012, p. 26), em sua obra Educação e Formação para o trabalho no Brasil, a reestruturação do setor produtivo e de serviços, tanto em nível internacional quanto no Brasil, tem influenciado fortemente a relação Trabalho e Educação no sentido de restringir o acesso às tecnologias de ponta, impedindo o País de criar condições para o progresso científico e tecnológico tornando-o, dessa forma, mais dependente do capital estrangeiro, alicerçando cada vez mais a subsunção da classe trabalhadora ao capital.

No Brasil, as mudanças no mundo do trabalho ressignificaram as relações trabalhistas, e, no âmbito do novo processo de trabalho, passou-se a atribuir ao trabalhador a responsabilidade por estar ou não desempregado, qualificado, apto para o mercado, reforçando a característica do individualismo, um dos elementos marcantes do capitalismo.

Frigotto (2005) analisa a concepção sobre o Trabalho no contexto da globalização do capital e do desemprego estrutural, demonstrando que a relação existente entre a Educação básica de nível médio e o mundo do Trabalho ocorre de forma fragmentada e não fundamentada no ensino médio de qualidade, simplesmente para atender às necessidades do capital e não para cumprir os princípios da justiça social e preparação para o trabalho. Em suas palavras, "[...] não cumprimos nem o imperativo da justiça social, nem da preparação para o trabalho complexo e, muito menos, um contingente de jovens com possibilidade de produzirem ciência e tecnologia" (p. 16). O autor conclui que a relação entre ensino médio e mercado de trabalho não deve ser marcada pelo imediatismo que impera neste, tampouco se caracterizar por manter vínculo imediato com o trabalho produtivo, isso porque: 
Trata-se de uma reação mediata. Sua relação intrínseca dá-se com o trabalho na sua natureza ontocriativa. De forma diversa, a formação profissional específica, para ser efetiva, tem que ter como condição prévia à educação básica (fundamental e média) e articular-se, portanto, a ela e às mudanças científico-técnicas do processo produtivo imediato. (FRIGOTTO, 2005, p. 16).

\section{O estágio de nível médio nas escolas de ensino fun- damental da Prefeitura de Maracanaú}

O estágio de nível médio nas escolas da Prefeitura ocorre através da Secretaria Municipal de Educação do Município, que recebe a maioria dos estagiários de nível médio, contratados pela Prefeitura. Em setembro de 2015, essa secretaria possuía em seu quadro de pessoal 4.243(quatro mil duzentos e quarenta e tres) servidores com diversos vínculos empregatícios, e 293(duzentos e noventa e tres) estagiários de nível médio, compondo 7\% do quadro de pessoal da Secretaria de Educação do Municípo, lotados nas secretarias das escolas municipais, dando suporte à direção da unidade escolar.

Para facilitar a compreensão e análise dos dados coletados na pesquisa subdividiu-se a temática em três tópicos: a) Concepção de estágio; b) 0 estágio em si: expectativa, a vivência do estágio e o vir a ser; c) Precarização do trabalho juvenil, cada uma das quais será descrita de modo condensado nos Quadros 1, 2, e 3, apresentados na continuidade, que reúnem o marco legal (apenas os dois primeiros), o referencial e os relatos extraídos dos grupos focais/entrevistas pertinentes 


\section{Quadro 1 - Concepção de estágio}

\begin{tabular}{|c|c|c|}
\hline Marco legal & Literatura & Grupo focal/Entrevistas \\
\hline \multirow{3}{*}{$\begin{array}{l}\text { Lei no } 11.788 \text {, de } 25 \text { de setem- } \\
\text { bro de } 2008 \text { "Art. } 1 \text { - Estágio é } \\
\text { ato educativo escolar super- } \\
\text { visionado, desenvolvido no } \\
\text { ambiente de tra-balho, que } \\
\text { visa à preparação para o traba- } \\
\text { lho produtivo de educan- dos } \\
\text { que estejam freqüentando } \\
\text { o ensino regular em institui- } \\
\text { cões de educação superior, } \\
\text { de educação profissional, de } \\
\text { ensino médio, da educação } \\
\text { especial e dos anos finais do } \\
\text { ensino fundamental, na moda- } \\
\text { lidade profissional da edu- } \\
\text { cação de jovens e adultos." }\end{array}$} & \multirow{3}{*}{$\begin{array}{l}\text { Para Mészáros (2008, p. } 350 \text { ), "A educa- } \\
\text { ção institucionalizada, especialmente } \\
\text { nos últimos } 150 \text { anos, serviu - no seu } \\
\text { todo - ao propósito de não só fornecer } \\
\text { os conhecimentos e o pessoal necessá- } \\
\text { rio à máquina produtiva em expansão } \\
\text { do sistema do capital, como também } \\
\text { gerar e transmitir um quadro de valores } \\
\text { que legitima os interesses dominantes } \\
\text { [...] (Grifos nossos)" }\end{array}$} & $\begin{array}{l}\text { "É preparo para o trabalho, experi- } \\
\text { ência, é aprender uma profissão." } \\
\text { (Plutão). }\end{array}$ \\
\hline & & $\begin{array}{l}\text { "Considero como os dois, como um } \\
\text { trabalho e como um complemento } \\
\text { ao ensino." } \\
\text { (Halley). }\end{array}$ \\
\hline & & $\begin{array}{l}\text { "Eu considero como trabalho } \\
\text { mesmo, porque tenho horário para } \\
\text { entrar e para sair, tenho tarefas } \\
\text { para realizar nesse horário, recebo } \\
\text { bolsa que por sinal é muito pouco, } \\
\text { faço tudo que os outros servidores } \\
\text { fazem, então... pra mim é trabalho." } \\
\text { (Caronte). }\end{array}$ \\
\hline \multirow[t]{5}{*}{$\begin{array}{l}\text { Lei } n^{\circ} \mathbf{1 . 3 4 9} \text {, de } 14 \text { de novem- } \\
\text { bro de } 2008 \text { "Art. } \mathbf{2}^{\circ} \text {. } \\
\text { Fomentar o aprendiza- do, } \\
\text { complementar o ensino e pre- } \\
\text { parar o jovem para sua inser- } \\
\text { ção no mercado de trabalho." }\end{array}$} & \multirow{5}{*}{$\begin{array}{l}\text { Colombo et al. (2014, p. 173) função do } \\
\text { estágio: "reforçar o aprendizado profis- } \\
\text { sional do educando através da experi- } \\
\text { ência prática. Esta se torna ainda mais } \\
\text { proveitosa quando está ligada à reali- } \\
\text { dade econômica em que a escola está } \\
\text { inserida, pois, com a interação - entre } \\
\text { o aluno, a empresa e a escola -, há um } \\
\text { ganho pedagógico para todos, visto } \\
\text { que grande parte da bagagem teórica } \\
\text { da sala de aula vai de encontro à situa- } \\
\text { ção concreta e do cotidiano, no mundo } \\
\text { econômico real". } \\
\text { Para Colombo et al. (2014, p. 172), "Os } \\
\text { debates em torno de uma nova legisla- } \\
\text { cão sobre estágio ocorrida no Congresso } \\
\text { Nacional Brasileiro, a partir da primeira } \\
\text { década do século XXI, demonstraram a } \\
\text { existência de um confronto entre aque- } \\
\text { les que defendiam o estágio com foco } \\
\text { no interesse da escola e os que focavam } \\
\text { o interesse das empresas.". }\end{array}$} & $\begin{array}{l}\text { "Eu considero como complemento } \\
\text { ao ensino, porque antes eu era } \\
\text { muito tímida na escola que eu } \\
\text { estudo e quando comecei meu } \\
\text { estágio tive que atender os pais dos } \\
\text { alunos, então tive que perder a timi- } \\
\text { dez e isso me ajudou muito na apre- } \\
\text { sentação dos trabalhos na escola } \\
\text { em que eu estudo." (Éris). } \\
\end{array}$ \\
\hline & & $\begin{array}{l}\text { "É forma de qualificar o estudante } \\
\text { para ter diferencial nas seleções de } \\
\text { trabalho no futuro." (superv. "H”). }\end{array}$ \\
\hline & & $\begin{array}{l}\text { "É uma boa intenção da Prefeitura } \\
\text { em ajudar os meninos." } \\
\text { (superv. "M”). }\end{array}$ \\
\hline & & $\begin{array}{l}\text { "É uma prática extremamente } \\
\text { importante para o Sistema, pois } \\
\text { à medida que estão aprendendo } \\
\text { também estão trabalhando." } \\
\text { (GSME, grifos nossos). }\end{array}$ \\
\hline & & $\begin{array}{l}\text { Tem mais um cunho social do que } \\
\text { educacional, tendo em vista a } \\
\text { condição econômica das famílias } \\
\text { dos estagiários." (GSRH). }\end{array}$ \\
\hline
\end{tabular}


Após análise dos dados, compreendeu-se que a concepção de estágio normatizada pelo marco legal institui o estágio como prática educativa que prepara o jovem para o trabalho produtivo e sua inserção no mercado, maquiando, assim, essa relação de potencial trabalhador a ser explorado pelas forças capitalistas, e completamente desprotegido das leis trabalhistas e previdenciárias, utilizando-se do discurso de "prática educativa".

Do ponto de vista teórico, observou-se que a Educação institucionalizada reforça os ditames do capital, preparando o trabalhador para a exploração, legitimando os valores da classe dominante. Assim, o mercado dita a perspectiva de atuação da formação do trabalhador de acordo com as suas necessidades.

Os achados na pesquisa com os gestores públicos revelaram que a concepção de estágio de nível médio significa utilização de mão de obra de baixo custo, necessária portanto para o sistema de Educação local funcionar na perspectiva de redução dos gastos públicos a partir desse tipo de contratação, apropriando-se da força de trabalho juvenil para alavancar os processos administrativos e de apoio à gestão escolar no âmbito da Secretaria Municipal de Educação (SME).

Para os supervisores de estágio, essa prática também significa inclusão social e preparação para a concorrência pela disputa de trabalho formal no mercado, portanto, nessa perspectiva, o estágio nem significa formação nem trabalho, mas um vir a ser indefinido, com perspectivas positivas e ao mesmo tempo duvidosas de inserção no mundo do trabalho.

Os estagiários observaram que a prática do estágio significa oportunidade de consumo, de acessar os bens e serviços disponíveis no mercado a partir do recebimento da bolsa-auxílio e ajuda financeira familiar.

\section{Quadro 2 - 0 estagiário em si: expectativas, a vivência do estágio e o vir a ser}

\begin{tabular}{|l|l|}
\hline Literatura & Grupo focal/Entrevistas \\
\hline Ramos (2009, p. 172, grifos nossos) “A inicia- & "Eu esperava que o valor da bolsa fosse maior." \\
ção ao mundo do trabalho desenvolve-se & (Júpiter, grifo nosso). \\
por meio de estágios e, em média, 30\% dos & \\
estudantes acima de 16 anos participam, no & \\
entanto, estes não são acompanhados pela & "Pra mim, foi mais do que eu esperava, porque além \\
escola e terminam sendo uma atividade & de eu sair de casa e pegar no meu dinheiro eu adquiri \\
individual, cabendo aos estudantes fazer as & mais experiência e responsabilidade, então supe- \\
reflexões necessárias para a análise crítica e & rou." (Namaka, grifo nosso). \\
criativa do processo de trabalho, do produto, \\
das relações sociais no mundo do trabalho e \\
consigo mesmo."
\end{tabular}

Fonte: Elaboração da autora (2016) 


\begin{tabular}{|c|c|}
\hline $\begin{array}{l}\text { Stolz (2005) "[Na Alemanha,] quem procura na } \\
\text { Internet por oportunidades de trabalho para jovens } \\
\text { profissionais de hoje encontra lá especialmente } \\
\text { estágios [...] Nas últimas quatro semanas surgiram } \\
3.320 \text { novas posições de estágio e apenas } 1.560 \\
\text { postos de trabalho permanentes para os novos } \\
\text { operadores." }\end{array}$ & $\begin{array}{l}\text { "Me sinto mais preparado para o trabalho porque já tenho } \\
\text { mais ou menos uma noção de como é no mercado de traba- } \\
\text { Iho, já posso dizer que tenho uma experiência, acho que é } \\
\text { isso!" (Makemake). }\end{array}$ \\
\hline \multirow{5}{*}{$\begin{array}{l}\text { Castel (2012, p. 475, grifo nosso) } \\
\text { Bloco periférico : [[...] trata-se das ocupações instá- } \\
\text { veis, sazonais, intermitentes. Esses "trabalhadores } \\
\text { periféricos" estão entregues à conjuntura. Sofrem } \\
\text { prioritariamente os contragolpes das variações da } \\
\text { demanda de mão de obra. Constituídos majorita- } \\
\text { riamente por imigrantes, por mulheres e jovens } \\
\text { sem qualificação [...]. Têm os salários mais baixos } \\
\text { e são os menos cobertos pelos direitos sociais. } \\
\text { Acampam nas fronteiras da sociedade salarial } \\
\text { muito mais do que dela participam integralmente". }\end{array}$} & $\begin{array}{l}\text { "Eu esperava até que as pessoas nem ligasse pra mim, meu } \\
\text { primeiro trabalho foi digitar uma planilha, eu achava que } \\
\text { os professores eram mais chatos. Mais foi ótimo, então o } \\
\text { estágio superou." (Terra, grifo nosso). }\end{array}$ \\
\hline & $\begin{array}{l}\text { "A gente ajuda muito dentro da escola. Vou sentir muita } \\
\text { falta do estágio, porque me sinto útil [...]" (Namaka, grifo } \\
\text { nosso). }\end{array}$ \\
\hline & $\begin{array}{l}\text { "O Estágio me fez decidir ser professora de educação espe- } \\
\text { cial, eu acho que o estágio me ajudou nisso." (Éris) }\end{array}$ \\
\hline & $\begin{array}{l}\text { "O estágio serviu para eu saber o que eu não quero, que é } \\
\text { trabalhar com criança." (Eros, grifo nosso). }\end{array}$ \\
\hline & $\begin{array}{l}\text { "Fazer esse estágio aqui na prefeitura abriu as portas pra } \\
\text { gente, que geralmente não se abre em outro lugar." (Disno- } \\
\text { mia). }\end{array}$ \\
\hline
\end{tabular}

O momento da pesquisa de campo proporcionou à pesquisadora uma riqueza de conhecimentos e experiência e o desvelamento de uma realidade pouco conhecida - a da vivência e do vir a ser do estagiário nessa relação construída contraditoriamente. Identificou-se no conteúdo das falas dos jovens a presença das categorias remuneração, relação social, sobrecarga de trabalho, experiência e hierarquização, linguagem proferida por trabalhadores de qualquer organização, o que impede que se ignore a interferência da lógica capitalista nos modos de vida juvenis e em suas interações com (e no) estágio de nível médio nessa instituição.

Depreende-se da análise dos dados que o estágio para os jovens estudantes produz significados, relações e vivências voltadas para a interação social, perspectivas futuras, descobertas e escolhas, transcendendo a execução de tarefas administrativas pouco atrativas e a possibilidade real de acesso a bens e serviços com a bolsa-auxílio, construindo, desse 
modo, uma teia de relações e "aprendizado". Percebeu-se em geral um sentimento de utilidade, de dever cumprido, e de descoberta do que não aspirar para o futuro profissional, ou seja, do vir a ser, a partir da vivência do estágio, consistindo na definição da profissão futura, por confirmação ou eliminação de possibilidades.

A vivência no estágio portanto oportunizou-lhes a aquisição de responsabilidades que, em suas percepções, possibilitarão sua entrada no mercado de trabalho futuro. Por outro lado, os relatos apontam a falta de capacitação e a baixa remuneração, e as semeIhanças na sobrecarga de atividades com os demais servidores, elementos que definem claramente a precarização do trabalho juvenil. As expectativas futuras, após o encerramento do estágio, se configuram a partir de perspectivas e esperanças de ingresso no mercado de trabalho, que se apresenta seletivo, competitivo e excludente.

Paradoxalmente, revelou-se um contexto institucional de pouco aprendizado para o trabalho, dissociado da instituição de ensino e supervisionado por servidores com pouco ou nenhum conhecimento sobre o estágio e seu marco legal.

\section{Quadro 3 - Precarização do trabalho juvenil}

\begin{tabular}{|c|c|}
\hline Literatura & Grupo Focal/Entrevistas \\
\hline $\begin{array}{l}\text { Para Antunes (1999, p. 16), "[...] Estes são } \\
\text { desregulamentados, são flexibilizados de } \\
\text { modo a dotar o capital do instrumental } \\
\text { necessário para adequar-se a sua nova fase." }\end{array}$ & $\begin{array}{l}\text { "Acho que deveria ser melhor, melhorar o } \\
\text { valor da bolsa e oferecer curso, pois traba- } \\
\text { Ihamos igual ou até mais que os outros servi- } \\
\text { dores e recebemos bem menos." (Eros). }\end{array}$ \\
\hline \multirow{2}{*}{$\begin{array}{l}\text { Gutiérrez (apud CATANI; GIGLIOLI, 2008, } \\
\text { p. } 67 \text {, grifos nossos) "[...] as alternativas de } \\
\text { ocupação juvenil cada vez mais se asso- } \\
\text { ciam aos setores de baixa produtividade e } \\
\text { a relações trabalhistas precárias, distan- } \\
\text { ciando-se dos segmentos mais modernos } \\
\text { da economia, situação que contribui para o } \\
\text { acirramento da exclusão social”. }\end{array}$} & $\begin{array}{l}\text { "Os coordenadores falam que quando a } \\
\text { gente sair o trabalho vai ficar pesado para } \\
\underline{\text { eles }[. . .] " \text { (Vesta, grifos nossos). }}\end{array}$ \\
\hline & $\begin{array}{l}\text { "Vejo um aspecto negativo nesse programa } \\
\text { que é a substituição da mão de obra efetiva } \\
\text { por uma mão de obra barata, porque o muni- } \\
\text { cípio não tem feito concurso pra essas áreas } \\
\text { administrativas." (GSME, grifos nossos). }\end{array}$ \\
\hline $\begin{array}{l}\text { Antunes }(1999, \text { p. } 44) \text { “[...] essas diversas } \\
\text { categorias de trabalhadores têm em comum } \\
\text { a precariedade do empre- go e da remune- } \\
\text { ração; a desregulamentação das condi- ções } \\
\text { de trabalho em relação às normas legais } \\
\text { vigentes ou acordadas e a conseqüente } \\
\text { regressão dos direitos sociais". }\end{array}$ & $\begin{array}{l}\text { "Reafirmo que é uma mão de obra barata, } \\
\text { de forma consciente ou não, intencionada } \\
\text { ou não, mas acaba se constituindo nisso sim } \\
\text { e a gente dá graças a Deus tê-los." (GSME, } \\
\text { grifos nossos). }\end{array}$ \\
\hline
\end{tabular}


Antunes (1999, p. 53, grifo nosso) Abrange a periferia da força de trabalho "[...] empregados em tempo parcial empregados casuais, pessoal com contrato por tempo determinado, temporários, subcontratação e treinados com subsídio público, tendo ainda menos segurança de emprego do que o primeiro grupo periférico".

Antunes (2000, p. 102, grifo nosso) “[...] também os trabalhadores improdutivos, aqueles cujas formas de trabalho são utilizadas como serviço, seja para uso público ou para o capitalismo, e que não se constituem como elemento diretamente produtivo, como elemento vivo do processo de valorização do capital e de criação de mais-valia."

Frigotto (2005, p. 7, grifo nosso) "O ideário da globalização, em sua aparente neutralidade, cumpre um papel ideológico de encobrir os processos de dominação e de desregulamentação do capital e, como conseqüência, a extraordinária ampliação do desemprego estrutural, trabalho precário e aumento da exclusão social."

Andrade e Amaral (2012, p. 29) (relação Educação e Trabalho na Alemanha e no Brasil) "[...] [sic] O desemprego e a precarização do trabalho passam a compor a nova realidade da estrutura produtiva mundial, acrescida do baixo dinamismo da produção e da forte oscilação no nível de atividade econômica mundial”.
"Eu acho que num momento de crise tudo bem a gente enxergar como uma mão de obra de baixo custo, pois a contratação deles não interfere nos índices da lei de responsabilidade fiscal, essas contratações são motivadoras, especialmente em anos de crise." (GSRH).

"O estágio deveria ter uma estrutura melhor para gente estagiário, pois nesse tempo todo, não teve nenhuma reunião, formação, nada, e tem muita coisa pra gente fazer, logo que a gente entrou era só um estagiário para cada turno, aí fica muito pesado." (Netuno, grifos nossos).

"Quando os professores saem da sala de aula pro intervalo, nós é quem ficamos no pátio olhando os alunos, ficamos na secretaria emitindo declaração, digitando, fazemos de um tudo. Organiza documentos e atende os pais. Faço o que precisar." (Caronte, grifos nossos).

"É muito bom ter estagiários aqui na secretaria da escola porque eles ajudam nessa parte toda de manutenção desse trabalho do dia a dia, eles trabalham e aprendem muito aqui." (superv. “M”, grifos nossos).

Ao se analisar o contexto da sociedade capitalista, evidenciou-se que com a predominância da ideologia dominante, que mascara as relações de exploração do trabalhador com o discurso de produtividade, criatividade, inclusão social, solidariedade e polivalência, visando aumentar os lucros com a espoliação do trabalho humano e o desmonte dos direitos trabalhistas, a separação entre o saber e o fazer, entre a Educação e o Trabalho, imbuída da noção de capital humano, de sociedade do conhecimento e da empregabilidade, constitui o 
aparato ideológico que reforça as desigualdades sociais e coloca o trabalhador como centro da exploração para geração de riquezas em prol da classe dominante

Com base nesse contexto, e no referencial teórico adotado, investigou-se a possibilidade de a prática de estágio de nível médio se configurar em forma de trabalho precarizado. Desse modo, permearam-se as relações intra institucionais, por meio do contato direto com o nível mais alto da gestão administrativa municipal, responsável pela gestão do Programa Estagiar, perpassando-se o nível intermediário, o da supervisão de estágios, até se chegar ao próprio estagiário.

Nessa dinâmica investigativa, identificou-se, nos discursos apresentados tanto pela supervisão quanto pela gestão, a presença do aparato ideológico que reforça a exploração do trabalho mediante a ideologia dominante, principalmente ao referir-se ao estágio e ao próprio estagiário como inclusão social, por integrarem uma classe social baixa com necessidades básicas imediatas atendidas pelo recebimento da bolsa-auxílio, configurando-se como ajuda do município aos seus munícipes.

Desse modo, observou-se a presença da precarização do trabalho mediante a contratação dos estagiários de nível médio, representada pela sobrecarga do trabalho sob sua responsabilidade e a baixa remuneração percebida pelo seu desempenho, pela inexistência dos encargos sociais e dos direitos trabalhistas e previdenciários, e pelo discurso proferido pela gestão e supervisão ressaltando o "aprendizado" do estagiário com essa iniciativa, que na prática consiste em aprender fazendo, especificamente as atividades administrativas da escola (campo de prática). Desse modo, vai-se reproduzindo o trabalho precarizado, mascarado mediante o contrato de estágio, que legaliza essa relação.

A confirmação da existência de relação direta de precarização do trabalho na contratação de estágios de nível médio, levando-se em consideração a histórica e crescente escassez de Recursos Humanos para o desempenho de funções administrativas na Administração Pública, proveio das revelações categóricas do GSME nesse sentido, derivadas das distorções percebidas no Programa com a atribuição de múltiplas tarefas aos estagiários.

Tal afirmação foi confirmada pelo grupo focal, quando seus integrantes revelaram estar sobrecarregados e se perceberem realizando atividades inerentes ao servidor público efetivo, conforme já mencionado, essa perspectiva foi reforçado pela fala do GSRH assegurando que os estagiários complementam o quadro de servidores da Prefeitura. 


\section{Considerações Finais}

Conclui-se após esse estudo que os jovens investigados reproduzem suas ideias isentas de reflexão crítica sobre Formação, Trabalho e Estágio, onde esse, significa mudanças comportamentais, responsabilidade, disciplina, incremento na renda familiar e preparação para o trabalho, a partir da ótica do disciplinamento, significando ainda liberdade, uma estratégia de sair de casa, ou ainda como a descoberta de um novo portal, um direcionamento para a escolha de uma profissão futura, quer por identificação, quer por exclusão de uma determinada possibilidade em razão de não identificação.

O conhecimento aprofundado da realidade institucional favoreceu a produção reflexiva sobre a prática do estágio de nível médio, que se mostrou distante da possibilidade do desenvolvimento de uma prática criativa e transformadora, e bem aproximado de uma prática de gestão de pessoas, caracterizada pela precarização do trabalho juvenil a partir da inexistência dos direitos trabalhistas e previdenciários e da realização de diversas atividades sem relação direta com o plano de atividades de estágio e pela falta de capacitação dos envolvidos diretamente com o campo de estágio.

Trata-se esta investigação de estudo não esgotado, que contempla questões e provoca reflexões capazes de contribuir para a definição de agenda política local que possibilite a formulação de Políticas articuladas de Juventude(s). Procurou-se mostrar o cenário do instituto de estágio de nível médio em instituição pública municipal, seu distanciamento da política de Educação e do Trabalho digno, bem como a falta de articulação com as demais políticas direcionadas para a(s) Juventude(s).

Os dados analisados apontam para certa estagnação da instituição em não elaborar política interna de gestão de pessoas para o acompanhamento desses jovens na perspectiva de contribuir para a complementação de sua formação a partir do instituto de estágio, sugerindo o desafio de se avaliar o Programa que absorve esses estudantes, sob a perspectiva do estágio em seu aspecto didático-pedagógico, possibilitando desse modo a minimização/ eliminação do viés da precarização do trabalho juvenil através dos contratos de estágios de nível médio, atualmente respaldados pelo arcabouço legal que favorece os interesses dominantes com a contratação dessa mão de obra de baixo custo e vulnerabilidade social, introduzindo o jovem, já desde cedo, no seu primeiro contato com o mundo do trabalho numa perspectiva de exploração de sua força produtiva, através do trabalho precarizado, como sendo algo inerente a sua condição de aprendiz e futuro trabalhador explorado, mediante negação de seus direitos sociais, trabalhistas e previdenciários. 


\section{Referências Bibliográficas}

ANDRADE, Francisca Rejane Bezerra; SANTOS, Geórgia Patrícia Guimarães dos; MACAMBIRA JÚNIOR, Leôncio José Bastos. Juventudes, Educação e Trabalho: o Programa Juventude Empreendedora na percepção dos jovens egressos. In: MACAMBIRA JÚNIOR, Leôncio José Bastos; ANDRADE, Francisca Rejane Bezerra (Org.). Trabalho e Formação profissional: juventudes em transição. Fortaleza: IDT, Uece, BNB, 2013. p. 233-260.

ANDRADE, Francisca Rejane Bezerra; AMARAL, Marcelo Parreira do. Educação e Trabalho no Século XXI: as condições sociais dos jovens no processo de transição escola-emprego na Alemanha e no Brasil. 0 público e o privado, revista da Universidade Estadual do Ceará, Fortaleza, n. 20, p. 29-54, 2012.

ANTUNES, Ricardo. Os Sentidos do Trabalho: ensaio sobre a afirmação e a negação do trabalho. 3. ed. São Paulo: Boitempo, 2000.

Adeus ao trabalho? Ensaios sobre as metamorfoses e a centralidade do mundo

do trabalho. 6. ed. São Paulo: Cortez, 1999.

BRASIL. Lei no 11.788, de 25 de setembro de 2008. Dispõe sobre o estágio de estudantes; altera a redação do art. 428 da Consolidação das Leis do Trabalho - CLT, aprovada pelo Decreto-Lei no 5.452, de 10 de maio de 1943, e a Lei no 9.394, de 20 de dezembro de 1996; revoga as Leis nos 6.494, de 7 de dezembro de 1977, e 8.859, de 23 de março de 1994, o parágrafo único do art. 82 da Lei no 9.394, de 20 de dezembro de 1996, e o art. 60 da Medida Provisória no 2.164-41, de 24 de agosto de 2001; e dá outras providências. DOU de 26.9.2008. Brasília, DF: Casa Civil da Presidência da República, 2008. Disponível em: <http://www.planalto.gov.br/ ccivil_03/_ato2007-2010/2 008/lei/I11788.htm>. Acesso em: 15 dez. 2013.

Lei no 8.069, de 13 de julho de 1990. Dispõe sobre o Estatuto da Criança e do Adolescente e dá outras providências. DOU de 6.7.1990 (retificado em 27.9.1990). Brasília, 
DF: Casa Civil da Presidência da República, 1990. Disponível em: <http://www.planalto.gov. br/ccivil_03/leis/L8069Compilado.htm>. Acesso em: 1o fev. 2014.

Lei no 5.692, de 11 de agosto de 1971. Dispõe sobre as diretrizes de Base da Educação. DOU de 12.8.1971. Brasília, DF: Casa Civil da Presidência da República, 1971. Disponível em: <http://www.planalto.gov.br/ccivil_03/leis/L5692. htm>. Acesso em: 15 jan. 2014

CASTEL, Robert. As metamorfoses da questão social: uma crônica do salário. 10. ed. Petrópolis, RJ: Vozes, 2012.

CATANI, Afrânio Mendes; GILIOLI, Renato de Sousa Porto. Culturas juvenis: múltiplos olhares. São Paulo: Editora Unesp, 2008

COLOMBO, Irineu Mário et al. Histórico e aplicação da legislação de estágio no Brasil. Educar em Revista, Curitiba, n. 53, p. 171-186, jul./set. 2014.

FRIGOTTO, Gaudêncio. Concepções e mudanças no mundo do trabalho e o ensino médio. In: ; RAMOS, Marise Nogueira; FRANCO, Maria Ciavatta Pantoja (Org.). Ensino médio integrado: concepção e contradições. São Paulo: Cortez, 2005. p. 3-17.

FUNDO DAS NAÇÕES UNIDAS PARA A INFÂNCIA. Unicef. O direito de ser adolescente: oportunidade para reduzir vulnerabilidades e superar desigualdades. Brasília, DF: Unicef, 2011.

INSTITUTO BRASILEIRO DE GEOGRAFIA E ESTATÍSTICA. IBGE. Síntese de Indicadores Sociais: uma Análise das Condições de Vida da População Brasileira 2010. Rio de Janeiro: MPOG, IBGE, Coordenação de População e Indicadores Sociais, 2010. (Série Estudos e Pesquisas, Informação Demográfica e Socioeconômica, ํㅡㄹ)

MARACANAÚ. Lei no 1.349, de 14 de novembro de 2008. Dispõe sobre a criação do Programa Estagiar no Município de Maracanaú e dá outras providências. Maracanaú, CE, 2008. Afixada. 
Lei no 912, de 27 de agosto de 2003. Autoriza a Criação do Programa Jovem Estagiário e adota outras providências. Maracanaú, CE, 2003. Afixada.

MÉSZÁROS, István. A Educação para além do capital. 2. ed. São Paulo: Boitempo, 2008.

PISTRAK, Moisey Mikhaylovich. Fundamentos da Escola do Trabalho. 4. ed. São Paulo: Expressão Popular Ltda., 2005.

RAMOS, Jeannette Filomeno Pouchain. Projeto educativo e político-pedagógico da escola de ensino médio: tradições e contradições na gestão e na formação para o trabalho. 2009. 245 f. Tese (Doutorado em Educação) - Universidade Federal do Ceará, Faculdade de Educação, Programa de Pós-Graduação em Educação Brasileira, Fortaleza (CE), 2009.

SOUSA, Antonia de Abreu et al. (Org.). Educação e Formação para o Trabalho no Brasil. Fortaleza: Editora da Universidade Federal do Ceará, 2012. v. 1.

STOLZ, Matthias. Generation Praktikum: Früher sollten Praktikanten bloß Erfahrungen für ihr künftiges Berufsleben sammeln. Heute werden sie als billige Arbeitskräfte eingesetzt. Zeit online, 31 März 2005. Disponível em: <http://pdf.zeit. de/2005/14/Titel_2fPraktikant_14. pdf>. Acesso em: 3 jan. 2016

TONET, Ivo. A Educação numa encruzilhada. In: MENEZES, Ana Maria Dorta de; FIGUEIREDO, Fábio Fonseca (Org.). Trabalho, Sociabilidade e Educação: uma crítica à ordem do capital. Fortaleza: Editora UFC, 2003. p. 201-219. 